\title{
Environmental Ethics
}

\author{
Mfonobong David Udoudom', Okpe ${ }^{2}$, Timothy Adie' ${ }^{2}$, Samuel Akpan Bassey $^{3}$ \\ ${ }^{I}$ Social Science Unit, School of General Studies, University of Nigeria, Nsukka, Nigeria. \\ ${ }^{2,3}$ Department of Philosophy, University of Calabar, Calabar, Cross River, 540242, Nigeria
}

\begin{abstract}
Environmental ethics is an area that investigates the question of which ethical norms are appropriate for governing human interactions with the natural environment. Considered a branch of applied or practical ethics, environmental ethics has only existed as a subject since the late 1970s. However, concern about environmental problems is growing, and many philosophers claimed that the mainstream of ethics' only focus on humans' relationships with other humans leaving behind clear theoretical framework for ethically evaluating the relationship among humans and the nonhuman natural world. In response to this position, they recommended that a new field of inquiry was needed to investigate this matter directly. This paper looks into the thrust of environmental ethics.
\end{abstract}

Keywords : Environmental ethics; Capitalism; Sustainable Development.

\section{Introduction}

Does the theme of environmental ethics have a place in our daily lives as individuals? Does it make a difference if the air we inhale and the water we drink turn out to be contaminated? Is there connection between the nature of food we eat and the expanding frequency of disease? Is environmental ethics a religious and moral issue - something that is of extreme concern, influencing us in our decisions of good and bad? Does it make a difference what sort of world we leave for our siblings and children to live in? Can any of us sincerely concede that our lone enthusiasm for our environment is the crude materials we extract from it? Obviously no; to some degree, each individual must feel grateful for the magnificence and grandeur of our current world. In truth, a large portion of us are insignificantly ungrateful that we totally look to our environment for all material things we need as humans. It is very difficult to make do without our environment, as to live without food, water or air. We as earth inhabitants owe our environment an obligation with each breath we take, drop of water we use and each munch of food we eat. The motivation behind this research is to show the aggregate voice rising that we are required to amend our relationship with our environment. This aggregate voice incorporates taught experimental researchers, religious scholars and committed philosophers.

\section{Review of Literature}

Modifying the relationship amongst humans and nature is a standout amongst the basic issues confronting our societies which must be managed properly today. With the expanding decay of our ecological world, environmental emergency is now required. Most individuals now understands that we can't depend on financial and legal techniques alone to take care of the issues of environmental decadence and people now have to be morally responsible . It is only after we have embraced a proper disposition towards nature and have set up right moral relationship between individuals and nature, then will we have the capacity to love and regard nature with honesty. Many scholars (most especially, Marxist) believed that the rise of the Industrial Revolution caused environmental decadency which is fast becoming man biggest problem (Gardiner, 397). The present-day atmosphere is quite different from the atmosphere that existed before the Industrial Revolution. Marx was very critical of capitalism; he thinks 
man's many problems, including environmental decadence, are tied to capitalism. Capitalism for Marx encourages globalization and competition within human species which leads to alienation of man from his product, labour process, species being and hence man cannot control those things in which he produces as it begins to act against him (Bassey, 1552). This has been the case of man in his physical environment, despite human beings marvelous technological breakthrough and accomplishments in which centuries ago seems beyond reach. Man could boast of space travel, internet, cars and other kind of unimaginable technological achievement, but still, these technological breakthroughs bring about negative effects on man's health and livelihood. Man still finds himself trying to solve problems in which he brought upon himself through the things he did create. Human's life span has been reduced compared to centuries ago, new forms of sickness and diseases are now evident in our societies. Air pollution, one of the leading environmental problems has been said to have worsen human and other species conditions for years (Brunekreef, 6661). Over the past "30 years, researchers have unearthed a wide array of health effects which are believed to be associated with air pollution" (Kelly, 613). Among them we can find respiratory diseases which include asthma, cardiovascular diseases, lung problem and even death. The World health Organization "estimates that some $80 \%$ of outdoor air pollution-related premature deaths were due to ischaemic heart disease and strokes, while $14 \%$ of deaths were due to chronic obstructive pulmonary disease or acute lower respiratory infections; and $6 \%$ of deaths were due to lung cancer" (Perez-Padilla, 458). In our today's world "nearly 30 million adults and children in the United States have been diagnosed with asthma. Asthma sufferers can be severely affected by air pollution. Air pollution can also pose serious health issues for the elderly and many other persons with heart or respiratory diseases. Some toxic chemicals released into out atmosphere such as benzene or vinyl chloride can cause nerve damage, cancer, birth defects, injury and in some cases, breathing these chemicals can even cause death (Ames, 568). Many other pollutants will often make their way up into the upper atmosphere, causing a thinning of the protective ozone layer. This has led to changes in the environment and dramatic increases in skin cancers and cataracts. The health, environmental, and economic implication of air pollution is significant highly. Among them are respiratory diseases (including asthma and changes in lung function), cardiovascular diseases, adverse pregnancy outcomes (such as preterm birth), and even death (Kelly, 614). In 2013, the World Health Organization concluded that outdoor air pollution is carcinogenic to humans (World Health Organization, 10). While climate change is a global process, it has very local impacts that can profoundly affect communities, not the least of which is air pollution. Every day, air pollution causes thousand of persons worldwide to fall sick leading to those persons staying away from work and school. Air pollution can also reduce agricultural profits running to millions of dollars every year. Other environmental problem; includes water pollution and environment exploitation has also caused devise negative effect on man. This has been caused by increase of capitalist mindset and capitalism in general. This is the crux of Karl Marx concept of alienation of human in a capitalist economic in his Economic and Philosophic Manuscripts of 1844. Due to these problems raised environmental ethics began to evolve.

Environmental ethics considers the ethical relationship between people and the natural world and tries to rationalize on the kind of decisions people make as regards their environment, which are: 
- Should we continue to cut down trees and rain forests for the sake of human consumption?

- Should we continue to manufacture petrol-driven cars when we have the technology to make cars which do not pollute the environment?

- Should we continue to exploit the earth to our selfish interest while on the long run it will cause more problems?

- Should we knowingly cause the extinction of other species and feed on them?

- What are our environmental obligations to future generations?

- Should humans be forced to live a simpler lifestyle in order to protect and preserve the environment, or we should enjoy it to the fullness to the determent of the future generations?

Most people recognize that our planet is in a bad way and we all seem to have an opinion on environmental issues, such as climate change or the use of four wheel drive cars in cities. The importance of environmental ethics is brought home daily by the news of global warming and its effect on our lives, both now and in the future. Environmental ethics has grown in importance in our times. However, there is no agreed ethics for environmental issues, and no universal international environmental code. Environmental ethics simply tries to answer the questions of how humans should relate to their environment, how we should use the Earth's resources and how we should treat other species. Moral equality theories extend equal consideration and moral status to animals by refuting the supposed moral relevance of the aforementioned special properties of human beings. Arguing by analogy, moral equality theories often extend the concept of rights to animals on the grounds that they have similar physiological and mental capacities as infants or disabled human beings. Some philosophers deny that animals warrant direct moral concern due to religious or philosophical theories of the nature of the world and the proper place of its inhabitants. One of the earliest and clearest expressions of this kind of view comes to us from Aristotle (384-322 B.C.E.). According to Aristotle, there is a natural hierarchy of living beings. The different levels are determined by the abilities present in the beings due to their natures. Closely related to Worldview/Religious theories are theories such as Immanuel Kant's (1724-1804). Kant developed a highly influential moral theory according to which autonomy is a necessary property to be the kind of being whose interests are to count directly in the moral assessment of actions (Kant, 1983, 1956). According to Kant, morally permissible actions are those actions that could be willed by all rational individuals in the circumstances. The important part of his conception for the moral status of animals is his reliance on the notion of willing. Peter Singer and Tom Regan are the most famous proponents of the view that we should extend moral standing to other species of animal. While both develop quite different animal ethics, their reasons for according moral status to animals are fairly similar. According to Singer, the criterion for moral standing is sentience: the capacity to feel pleasure and pain (Singer, 1974). For Regan, on the other hand, moral standing should be acknowledged in all "subjects-of-a-life": that is, those beings with beliefs, desires, perception, memory, emotions, a sense of future and the ability to initiate action (Regan, 1983/2004, ch. 7). So, while Regan and Singer give slightly different criteria for moral standing, both places a premium on a form of consciousness. For Singer, if an entity possesses the relevant type of consciousness, then that entity should be given equal consideration when we formulate our moral obligations. 
There are differences among scientists as to the exact cause and nature of environmental problems and how to solve them, and so there are differences in the approaches to environmental ethics; some think the traditional forms of ethical thought are good guides and some that these traditional forms (at least in the West) are too humancentered. An immense Millennium Ecosystem Assessment, supported by the United Nations, which included over 1,300 specialists from very nearly 100 countries, starts: "At the heart of this assessment is a stark warning. Human activity is putting such strain on the natural functions of the Earth and that the ability of the planet's ecosystems to sustain future generations can no longer be taken for granted" (Millennium Ecosystem Assessment, 2005a, p. 5). Paul Hawken says environmentalism is "the largest movement in the world," considering the number and force of environmental organizations around the globe (Hawken, 2007). If it appeared overstated, recall that the United Nations Conference on Environment and Development (UNCED) at Rio de Janeiro in 1992 united the biggest number of world leaders that have ever gathered to address any issue. That gathering drew 118 heads of state and government, appointments from 178 countries, 7,000 discretionary officials, 30,000 supporters of natural causes, and 7,000 columnists, to discuss Global warming. The primary effects on individuals and society is vulnerability, as atmosphere prompted dangers fuel an extensive variety of fundamental hazard conditions - exasperating natural anxieties which is already obvious. There are also several religious views towards our role and responsibility towards the natural world.

\section{Discussion}

\subsection{Christianity and Environmental Ethics}

The Christian book of Genesis in the Holy writ opines that God made the earth and place man in control to nurture it. God's order over man was that man ought to 'be productive and increment in number; fill the earth and stifle it' (Robinson, 49). Throughout the years numerous researchers have seen this verse of the sacred writing with debate. One would ponder what these verses of the sacred writing presuppose. How did God expect for man to control the earth and by what means would it be a good idea for it to resemble? A few researchers have translated this verse as giving man each privilege to abuse the earth. Many ethical issues in the biblical teaching are not often clear, and the idea that we humans have 'dominion' over the natural world is seen by many as anthropocentric. Peter Singer criticizes this tradition in his book Practical Ethics:

According to the Dominant Western tradition, the natural world exists for the benefit of human beings. God does not care how we treat it. Human beings are the only morally important members of this world. Nature itself is of no intrinsic value....Harsh as this tradition is, it does not rule out concern for the preservation of nature, as long as that concern can be related to human wellbeing (Singer, 45).

Singer points out that the teachings of Aristotle influenced Aquinas and continued to view humans as the only morally important beings - there being no intrinsic value in the natural world. However, some Christians think otherwise. Some Christians consider themselves to be being in charge of the world that was made by God of which they should be watchful on how they misuse it. Since man is one of God's manifestations, then individual exercises ought to be under domain of God. The book of Genesis asserted that God initially 
gave Adam and Eve the occupation of dressing and keeping the Garden of Eden. In the early piece of Genesis, we discover that people, made in God's image, are given the command to practice stewardship/administration mind over the environment and its creatures. We along these lines have an obligation first to God to take care of his creations. Being made in God's image is basically a command to take care of God's creation (Mk 10:42-45). Just in late decades have people built up the mechanical ability to survey the environmental soundness of creation all in all. Since we can comprehend the worldwide ecological circumstance more altogether than any time in recent memory, we are it could be said better situated to satisfy the stewardship order of Genesis 1 and 2 than at any other time. In the Genesis story of the garden, we are acquainted with human sin with its heartbreaking outcomes; people resisted God and did not need him around any longer. That broken association with God prompted to broken connections somewhere else as well. The calamities we find in environment talk articulately of the results of that broken relationship. Jesus needs us to be capable and good stewards until his arrival (Luke 12 v 41-48). Acting in acquiescence to this guideline gives an essential piece of our satisfaction as people. In our present day world this so regularly gets lost as we focus such a great amount on material things or financial objectives, for example, getting rich and capable. We neglect our responsibility to our brothers and environment for selfish interest. This is the problem of greed, ego and pride of Capitalism as expounded by Karl Marx and the love for mammon as been opined by the bible. Other, extraordinary savants and Religious pioneers like Mahavir, Buddha, Tagore and Gandhi all had confidence in the idea of keeping up a solid and cozy association with Nature (Nayak 2008). Islam shows us that God has proceeded and will keep on providing us with sufficient assets for unsurpassed. However, through man's abuse, this adjust may change. It is this individual covetousness of man that makes them waste these assets and deny other people who may require those assets. The Holy Quran cautions humanity in Chapter 7, verse 32 "O children of Adam!...eat and drink but exceed not the bounds; surely He does not love those who exceed the bounds" (Shams, 91). The general message of Islam is that it advances amicability by exhorting balance.

\subsection{Environmental Challenges, Sustainability and Solution}

Sustainable development (SD) is required, attractive, and naturally advantageous. The fundamental environmental worries of having societies with quality air, good food, water, less ozone layer downgrading, better biodiversity and natural surroundings assurance can be tended to while seeking after better environmental improvement. Sustainable fishery requires a global co-operative use restraint. Global co-operation is even more important for dealing with climate change. The global development community is looking for new solutions to traditional development issues such as economic stagnation, persistent poverty, hunger, malnutrition, and illness, as well as newer challenges like environmental degradation and globalization. Meanwhile, the threat of global climate change poses an unprecedented challenge to humanity. While climate change is important in the long run, it is crucial to recognize that (especially for the developing countries) there are a number of other development issues that affect human welfare more immediately - such as hunger and malnutrition, poverty, health which is heighten by environment problems. Climate change and sustainable development interact in a circular fashion. Climate change will have an impact on prospects for sustainable development, and in turn, alternative development paths will certainly affect future climate change. Seen from the development viewpoint, climate 
change vulnerability, impacts and adaptation are the main elements of concern. From the climate perspective, development pathways also determine emission levels, and they have implications for mitigation strategies as well. In other to sustain our climate from further so solutions have been proffered.

Geo-engineering : Geoengineering is the intentional, large-scale technological manipulation of the Earth's systems, often discussed as a techno-fix for combating climate change. Climate geoengineering technologies can be divided into three broad areas: so-called solar radiation management (reflecting sunlight to space), greenhouse gas removal and sequestration and weather modification. Geoengineering can refer to a wide range of techniques, including: blasting sulphate particles into the stratosphere or 'whitening' clouds to reflect the sun's rays; dumping iron particles in the oceans to nurture $\mathrm{CO} 2$-absorbing plankton; firing silver iodide into clouds to produce rain or genetically engineering crops so their foliage can better reflect sunlight (Boyd, 812).

The polluter pays principle (PPP) : is a basic economic idea that firms or consumers should pay for the cost of the negative externality they create. The polluter pays principle usually refers to environmental costs, but it could be extended to any external cost. In a purely free market, you would only face your private costs (Schwartz, 247). However, for goods with negative externalities, there are additional external costs, e.g. damage to the environment. This means the social cost of some goods are greater than the private cost. The polluter pays principle is simply the idea that we should pay the total social cost including the environmental costs. This requires some authority or government agency to calculate our external costs and make sure that we pay the full social cost. A simple example is a tax on petrol. When consuming petrol, we create pollution. The tax means the price we pay more closely reflects the social cost. The polluter pays principle is a way of 'internalising the externality'. It makes the firm / consumer pay the total social cost, rather than just the private cost. (Social cost $=$ private cost + external cost). The polluter pays principle is an important basis of international law. In 1972, the OECD wrote Guiding Principles concerning International Economic Aspects of Environmental Policies, stating: “... the polluter should bear the expenses of carrying out the above-mentioned measures decided by public authorities to ensure that the environment is in an acceptable state" (Das, 221). The polluter pays principle was incorporated into the 1992 Rio summit The declaration stated:

Principle 16: "National authorities should endeavor to promote the internalization of environmental costs and the use of economic instruments, taking into account the approach that the polluter should, in principle, bear the cost of pollution, with due regard to the public interest and without distorting international trade and investment." (Zillman, 221).

The difficulties of implementing the polluter pays principle don't undermine its validity. It just means in the real world it will be hard, if not impossible to get a perfect approximation of the external cost. As long as we get closer to the social cost, there will be an increase in economic welfare. However, some may argue that certain types of environmental pollution are so bad they should just be banned rather than taxing them, e.g. it is immoral to pollute a river and therefore we shouldn't allow it to occur even if the polluter does pay some financial cost. 


\section{Conclusion}

It is of fundamental importance to comprehend what kind of morally relevant information should be brought into social interactions between human and other non human phenomena. A key issue in environmental ethics is characterization of our "moral relationship" to future generations both human and non human. What obligations do we owe to the future? How should our current actions be influenced by their impact on the future? The aim of this article was to characterize and hopefully elucidate certain aspects of this "moral relationship." Our concern for the future should be seen as an expression of the principle of benevolence and recognition of the worth of all life and dignity.

\section{References}

Ames, B N. "Identifying Environmental Chemicals Causing Mutations and Cancer." Science 204.4393 (1979): 587-593. Web.

Ashton T.S., The Industrial Revolution, 1760-1830 (London: Oxford University Press, 1948)

Bassey, Samuel Akpan. "Karl Marx Alienation and the Nigerian Workers." Imperial Journal of Interdisciplinary Research (IJIR) 8th ser. 2.8 (2016): 1550-555. Web.

Boyd, Philip W. “Geopolitics of Geoengineering.” Nature Geoscience 2.12 (2009): 812-812. Web.

Brunekreef, Bert. "Air Pollution and Human Health: From Local to Global Issues." Procedia - Social and Behavioral Sciences. Vol. 2. N.p., 2010. 6661-6669. Web.

Das, Jatindra Kumar. Human Rights Law and Practice. S.L.: Prentice-Hall of India, 2016.

Gardiner, Stephen M. "A Perfect Moral Storm: Climate Change, Intergenerational Ethics and the Problem of Moral Corruption." Environmental Values 15.3 (2006): 397-413. Web.

Gardiner, Stephen M. "Ethics and Global Climate Change*." Ethics 114 (2004): 555-600. Web.

Hampicke, Ulrich. "Climate Change Economics and Discounted Utilitarianism." Ecological Economics 72 (2011): 45-52. Web.

Kain, P. "Kantian Ethics.” Philosophical Review 119 (2010): 104-108.

Kelly, Frank J. "Oxidative Stress: Its Role in Air Pollution and Adverse Health Effects." Occupational and Environmental Medicine 60.8 (2003): 612-616. Web.

Kelly, Frank J. "Oxidative Stress: Its Role in Air Pollution and Adverse Health Effects." Occupational and Environmental Medicine 60.8 (2003): 612-616. Web.

Perez-Padilla, Rogelio. "Hidden Respiratory Disease-Associated Deaths." International Journal of Tuberculosis and Lung Disease 12.4 (2008): 458-464. Print.

Robinson, Andrea L. "The Lost World of Adam and Eve: Genesis 2-3 and the Human Origins Debate." Science \& Christian Belief 28.1 (2016): 48-50. Web.

Sandler, Sergeiy. "A Strange Kind of Kantian: Bakhtin???s Reinterpretation of Kant and the Marburg School." Studies in East European Thought 67.3-4 (2015): 165-182. Web.

Schwartz, Priscilla. "The Polluter-Pays Principle." Research Handbook on International Environmental Law (2005): 243-261. Web.

Shams, Falahud Din. "Statement of Faith: Holy Bible and Holy Qurán." The Muslim Sunrise 91 (2011). 
World Health Organization. "WHO Air Quality Guidelines for Particulate Matter, Ozone, Nitrogen Dioxide and Sulfur Dioxide: Global Update 2005: Summary of Risk Assessment." Geneva: World Health Organization (2006): 1-22. Web.

Zillman, Donald N. Beyond the carbon economy: energy law in transition. Oxford: Oxford U Press, 2010. Print. 